\title{
A new species of Hortipes (Araneae, Corinnidae), the first spider with an insertable retrolateral tibial apophysis on the male palp
}

\author{
Rudy JOCQUÉ ${ }^{1}$, Jan BOSSELAERS ${ }^{2}$ and Arnaud HENRARD ${ }^{3}$ \\ ${ }^{1,2,3}$ Royal Museum for Central Africa, B 3080 Tervuren, Belgium. \\ Email: jocque@africamuseum.be \\ ${ }^{3}$ Earth and life Institute, Biodiversity research Center, UCL-17.07.04, \\ Bâtiment Carnoy, Croix du Sud, 5, B 1348, Louvain-la-Neuve, Belgium. \\ ${ }^{1}$ urn:1sid:zoobank.org:author:CF15016C-8CD1-4C9D-9021-44CA7DC7A5D5 \\ ${ }^{2}$ urn:1sid:zoobank.org:author:D6AD7414-3540-4F06-8631-8873450AA90C \\ 3urn:Isid:zoobank.org:author:E1B02E6E-D91C-43FE-8D8C-CD102EFEE3B4
}

\begin{abstract}
Hortipes gigapophysalis (Araneae, Corinnidae) is a new species described from both sexes from montane forest on Mt Nimba, eastern Guinea. The species is remarkable for its long, whip-shaped retrolateral tibial apophysis (RTA) on the male palp. The structure apparently has an insertable function as the epigyne of the female contains a separate set of ducts starting from a central concavity that is unique in the genus. This duct system is apparently meant to receive the supple RTA. This type of structural arrangement has never previously been found in spiders.
\end{abstract}

Keywords. genitalia, morphology, Corinnidae, Guinea, Mt Nimba.

Jocqué R., Bosselaers J. \& Henrard A. 2012. A new species of Hortipes (Araneae, Corinnidae), the first spider with an insertable retrolateral tibial apophysis on the male palp. European Journal of Taxonomy 26: 1-11. http://dx.doi. org/10.5852/ejt.2012.26

\section{Introduction}

With almost 70 known species, Hortipes Bosselaers \& Ledoux, 1998 is one of the largest Afrotropical genera (Bosselaers \& Jocqué 2000a). Most of the species live in the litter layer of dense forests and woodlands, hence its very wide distribution from West Africa to Ethiopia in the north and to large parts of South Africa in the south. However, the genus is entirely absent from miombo woodland and is therefore an excellent example of an Afrotropical spider genus with this type of distribution. The genus is also remarkable as an example of the range of complexity of genitalia that is met with in many spider genera. In Hortipes, the genitalia range from quite simple structures as in H. silvarum Ledoux \& Emerit, 1998 to complex configurations such as in H. sceptrum Bosselaers \& Jocqué, 2000a. The genus can therefore be considered as suitable for testing the evolution of genitalia in the context of sexual selection hypotheses (e.g. Eberhard \& Huber 1998; Huber 1995a; Jocqué 2002).

The present paper describes a new species in the genus that has a remarkable male palp provided with a very long retrolateral tibial apophysis (RTA) unlike any that has been found in spiders so far. 


\section{Material and Methods}

Specimens were observed and measured with a Leica M10 stereomicroscope. Photographs of the habitus were taken with a Leica MZ16 using the LAS automontage software. The female epigyne was detached from the abdomen, temporarily mounted in a clearing mixture of methyl salicylate and cedukol (Merck, Darmstadt) and observed with a Leitz Dialux 22 microscope and subject to automontage with the Syncroscopy software. For SEM photos, a palp was dried in HMDS, gold coated and examined and photographed with a JEOL $6480 \mathrm{LV}$ scanning electron microscope. The format for leg spination follows Platnick \& Shadab (1975), amended for ventral spine pairs according to Bosselaers \& Jocqué (2000b). The spine row sequences run from the base of segments towards the tip. Leg spine numbers between brackets refer to spines present in some instances and absent in others. All measurements are in millimeters.

A phylogenetic analysis was performed under implied weighting (Goloboff 1993) using the computer programmes PAUP 4.0 beta 10 (Swofford 2002), and TNT 1.1 (Goloboff et al. 2003, 2008) run on a dual-core Intel iMac under a Windows XP virtual machine (VMware Fusion 2, VMware, Inc., 3401 Hillview Avenue, Palo Alto, CA 94304, USA; Bugnion et al. 2000). For this purpose, the characters and data from Bosselaers \& Jocqué (2000a: 11-24) were used, with scores added for H. gigapophysalis (1:1, $2: 1,3: 1,4: 1,5: 1,6: 1,7: 2,8: 2,9: 0,10: 0,11: 1,12: 0,13: 1,14: 0,15: 0,16: 0,17: 0,18: 0,19: 0,20: 0,21: 0$, $22: 1,23: 1,24: 1,25: 1,26: 0,27: 1,28: 1,29: 1,30: 1,31: 1,32: 0,33: ?, 34: 0,35: ?, 36: 0,37: 0,38: 2,39: 3$, 40:1, 41:2, 42:0, 43:0, 44:0, 45:1, 46:?, 47:?, 48:?, 49:?, 50:?, 51:0, 52:1, 53:0, 54:7, 55:?, 56:?, 57:?, 58:?, 59:?, 60:0, 61:0, 62:0, 63:0, 64:0, 65:0, 66:0, 67:0, 68:1, 69:0, 70:0, 71:0, 72:0, 73:0, 74:1, 75:0, $76: 1,77: 0,78: 0,79: 0,80: 0,81: 1,82: 0,83: 2,84: 1,85: 1,86: 1,87: 0,88: 0,89: 0,90: 2)$. Moreover, the scoring for character 44, which had been inadvertently inverted in Bosselaers \& Jocqué (2000a: table 1), was rectified, and an extra character state was added to character 54 in order to score $H$. gigapophysalis. Bremer support values (Bremer 1988, 1994) for the preferred consensus tree, expressed as fit values, were calculated in TNT using Analyze / suboptimal, followed by Analyze / Traditional search / tree bisection reconnection (TBR) and Trees / Bremer Supports, retaining trees suboptimal up to 10 units of fit (TNT values, see Jocqué \& Bosselaers 2011: 274) and combining various numbers of replications (between 1 and 100) with various numbers of trees saved per replication (between 200 and 20000, inversely related to the numbers of replications) until the solution stabilized.

\begin{tabular}{|c|c|c|}
\hline \multicolumn{3}{|c|}{ Abbreviations } \\
\hline CL & $=$ & carapace length \\
\hline $\mathrm{CW}$ & $=$ & carapace width \\
\hline do & $=$ & dorsal \\
\hline DTA & $=$ & distal tegular apophysis \\
\hline dv & $=$ & dorso-ventral stretch of secundary tube system \\
\hline E & $=$ & embolus \\
\hline HMDS & $=$ & hexamethyldisilazane (CAS 999-97-3) \\
\hline MA & $=$ & median apophysis \\
\hline MRAC & $=$ & Royal Museum for Central Africa \\
\hline $\mathrm{mt}$ & $=$ & metatarsus \\
\hline PAUP & $=$ & phylogenetic analysis under parsimony \\
\hline $\mathrm{pdv}$ & $=$ & position of dorsoventral stretch \\
\hline pl & $=$ & prolateral \\
\hline plv & $=$ & prolateral ventral \\
\hline $\mathrm{rl}$ & $=$ & retrolateral \\
\hline $\mathrm{rlv}$ & $=$ & retrolateral ventral \\
\hline RTA & $=$ & retrolateral tibial apophysis \\
\hline
\end{tabular}




$\begin{array}{lll}\mathrm{ti} & = & \text { tibia } \\ \mathrm{TL} & = & \text { total length } \\ \mathrm{vt} & = & \text { ventral terminal }\end{array}$

\title{
Results
}

\author{
Class Arachnida Cuvier, 1812 \\ Order Araneae Clerck, 1757 \\ Family Corinnidae Karsch, 1880 \\ Genus Hortipes Bosselaers \& Ledoux, 1998 \\ Hortipes gigapophysalis sp. nov. \\ urn:Isid:zoobank.org:act:199C827C-56D9-4F42-A103-F063ACA0033F
}

Figs 1-5

\section{Diagnosis}

Males of $H$. gigapophysalis are easily recognized by the long, winding RTA; the female is characterized by the central depression and the separate duct systems in the epigyne. These characters are unique in the genus.

\section{Etymology}

The species is called gigapophysalis in view of the extraordinarily long retrolateral tibial apophysis on the male palp.

\section{Type material}

\section{Holotype}

ô (MRAC 239507): GUINEA, Mt. Nimba, Station de pompage Zié, alt. $1250 \mathrm{~m}, 07^{\circ} 40^{\prime} \mathrm{N}-008^{\circ} 22^{\prime} \mathrm{W}$, 03 Feb. 2012, hand collecting by A. Henrard, C. Allard, P. Bimou and M. Sidibé near Zié river, forest.

\section{Paratypes}

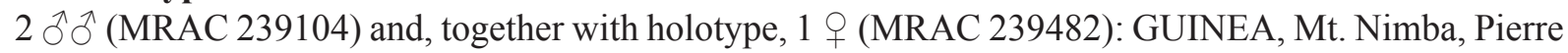
Richaud, Kaiser 1, alt. 1480 m, $07^{\circ} 39^{\prime} \mathrm{N}-008^{\circ} 22^{\prime}$ W, 7 Oct. 2011, hand collecting by A. Henrard and D. Vandenspiegel, at the entrance ( $\pm 4 \mathrm{~m}$ inside) of disused humid adit, under wood log.

\section{Description}

\section{Male}

MEAsurements. Total length 2.21 carapace 1.07 long, 0.87 wide; length of fe: I 0.89 , II 0.92 , III 0.72 , IV 1.07 .

Leg SpinATIOn. Fe: I plv 1-1-1 rlv 1-1-1; II plv 1-1-1 rlv 1-1-1; ti: I plv 1-1-1-1-1-1 rlv 1-1-1-1-1-1; II plv 1-1-1-1-1-1 rlv 1-1-1-1-1-1; IV pl 0-1-0 rl 0-1-0; mt: I plv 1-1-1 rlv 1-1-1; II plv 1-1-1 rlv 1-1-1; IV pl $1-0-1$ rl 1-0-1 vt 2.

Coloration. Carapace and legs yellow, with an orange tinge; sternum pale yellow, chelicerae, labium and endites yellow. Abdomen pale. (Fig. 1A-C).

PALP (Figs 2A-B, 4A-F). Tibia with central constriction. RTA very long, slender and coiled, narrowing from base to tip; cymbium subcircular, proximally with deep retrolateral fold, with few straight setae along retrolateral margin and group of chemosensory setae at distal dorsal tip; sperm duct appears at base of embolus, runs along retrolateral, posterior and prolateral margins of tegulum, fairly broad over 


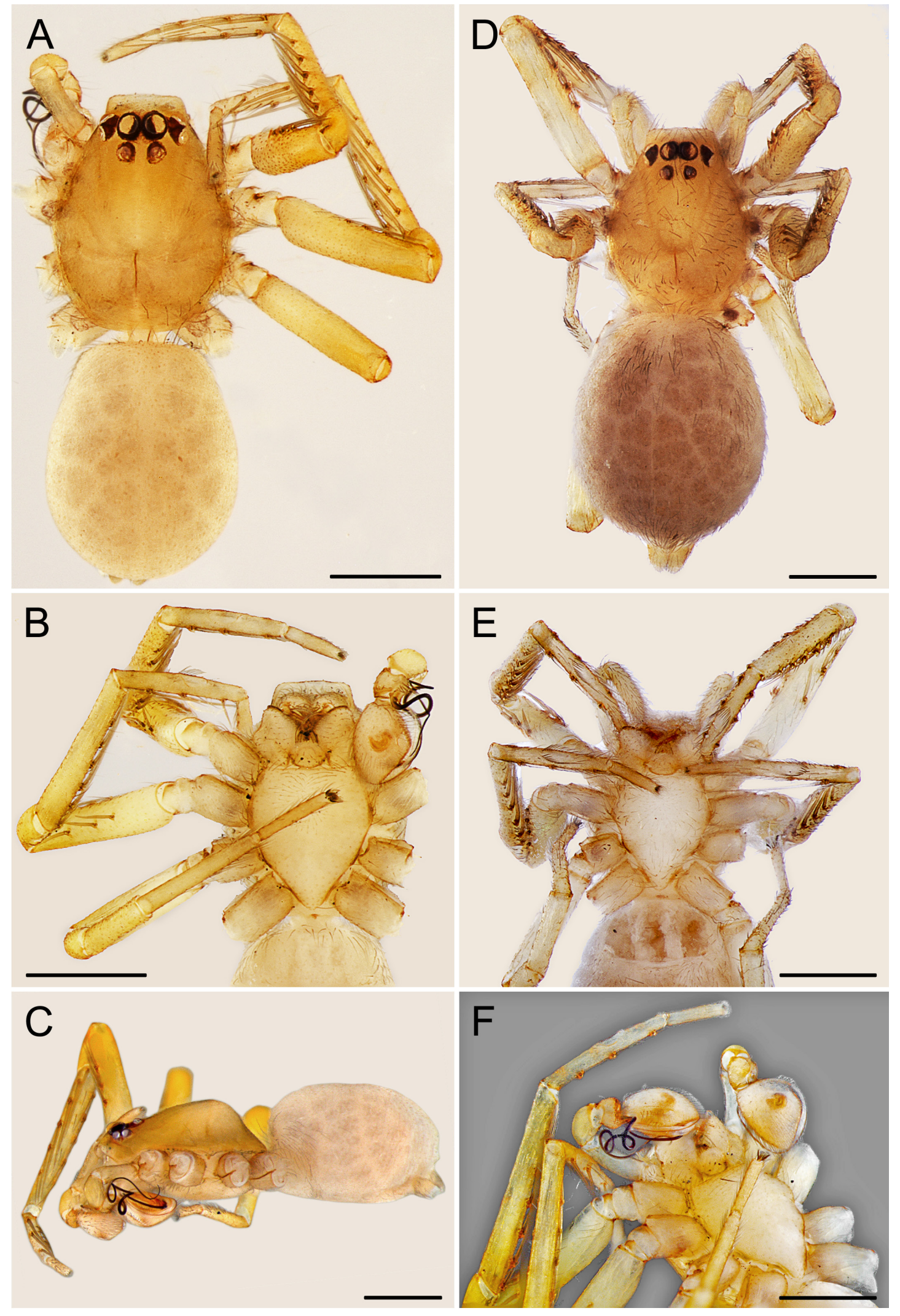

Fig. 1. Hortipes gigapophysalis sp. nov. A. Male habitus, dorsal view. B. Male prosoma, ventral view. C. Male habitus, lateral view. D. Female habitus, dorsal view. E. Female prosoma, ventral view (epigyne removed). F. Male prosoma, ventrolateral view. 

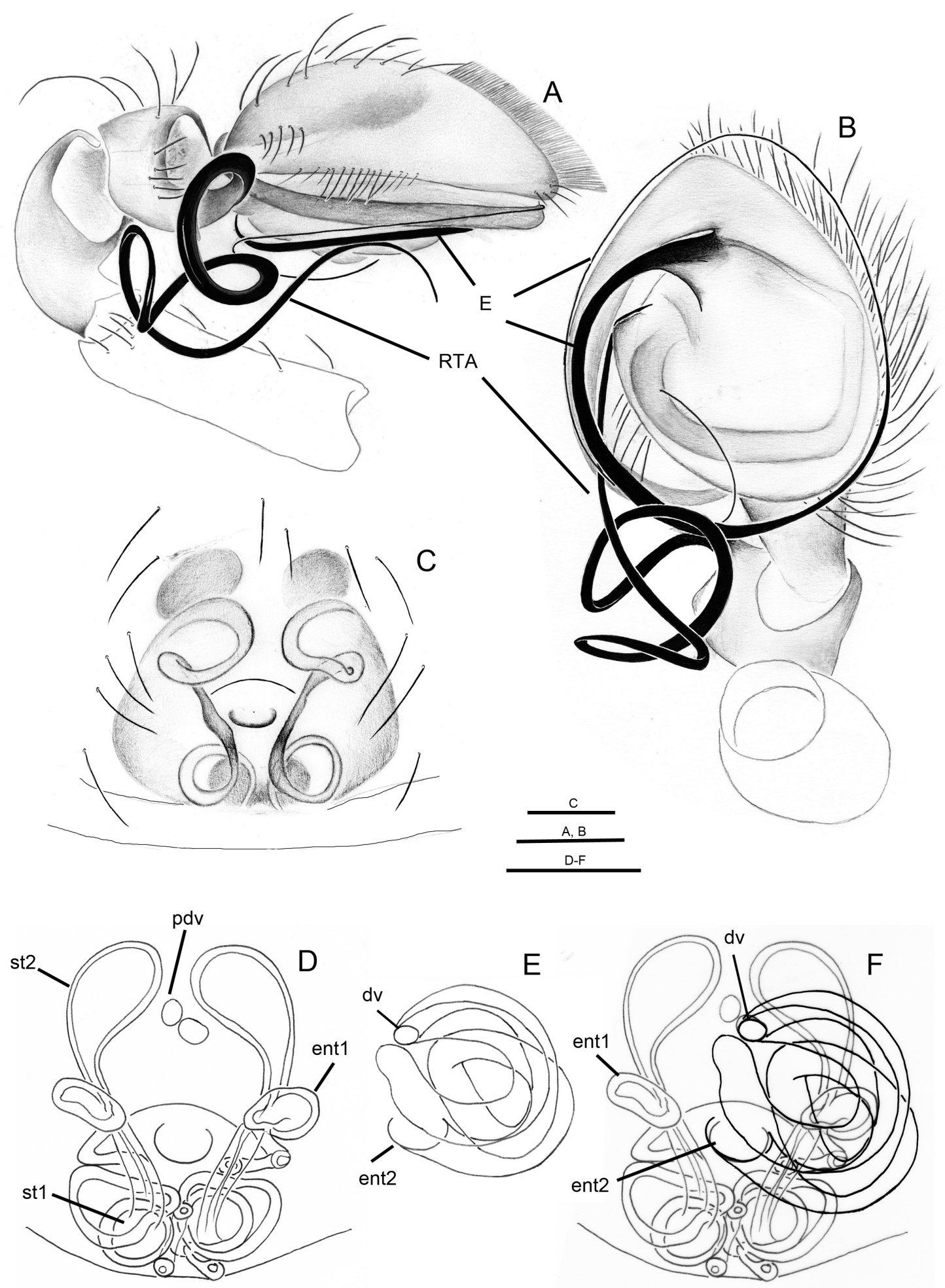

Fig. 2. Hortipes gigapophysalis sp. nov. A. Male palp, lateral view. B. idem, ventral view. C. Epigyne, ventral view. D. Epigyne, cleared, dorsal view, second system omitted. E. idem, primary system omitted. F. idem, both systems combined. E: embolus, ent1: entrance of insemination duct, ent2: entrance of secondary duct system, dv: dorso-ventral stretch of secondary duct system, pdv: position of dorsoventral stretch, RTA: retrolateral tibial apophysis, st1: spermathecae 1, st2: spermatheca 2. Scale bars: $100 \mu \mathrm{m}$. 
entire course except last quarter strongly narrowed before entering E; E originating at distal end of tegulum directed retrolaterad, very long, whiplike, looped over slightly more than some $500^{\circ}$. True MA, being an articulated tegular process inserted on a flexible membrane (Bonaldo 1997: 166) absent, but tegulum distally with membranous, translucent DTA, directed retrolaterad, curved back over $90^{\circ}$ ending near posterior margin of cymbium.

\section{Female}

MEAsuREMENTS. Total length 2.54; carapace 1.15 long, 0.85 wide; length of fe: I 0.95 , II 1.00, III 0.81, IV 1.11.

Leg SPINATION. Fe: I plv 1-1-1-(1) rlv 1-1-1; II plv 1-1-1 rlv 1-1-1-1-(1); ti: Palp do 1-0-0; I plv 1-1-1-11-1 rlv 1-1-1-1-1-1; II plv 1-1-1-1-1-1 rlv 1-1-1-1-1-1; mt: I plv 1-1-1 rlv 1-1-1; II plv 1-1-1 rlv 1-1-1; IV pl 0-0-1 rl 0-0-1 vt 2.

Coloration. Carapace, legs and chelicerae pale orange; sternum pale. Abdomen pale (Fig. 1D-F).

Genitalia. Epigyne with a central concavity and with convoluted tubes visible in transparency. Two funnel-shaped openings leading into a system of wide, very simple, thin-walled tubes, with blind ends (Fig. 2C-F). Thick-walled insemination ducts starting from slit-shaped lateral openings leading to two sets of spermathecae. Anterior pair oval, opening posteriorly into ducts leading towards posterior, globular pair. The systems are separate and there is no connection between them (Figs 2C-F, 3A-B).

\section{Variability}

Male paratypes (n=2) TL: 2.16 and 2.03; CL 1.10 and 0.89; CW 0.89 and 0.85. Spination identical.

\section{Distribution}

High altitude gallery forest (> $1200 \mathrm{~m}$ ) on Mt Nimba, Guinea.

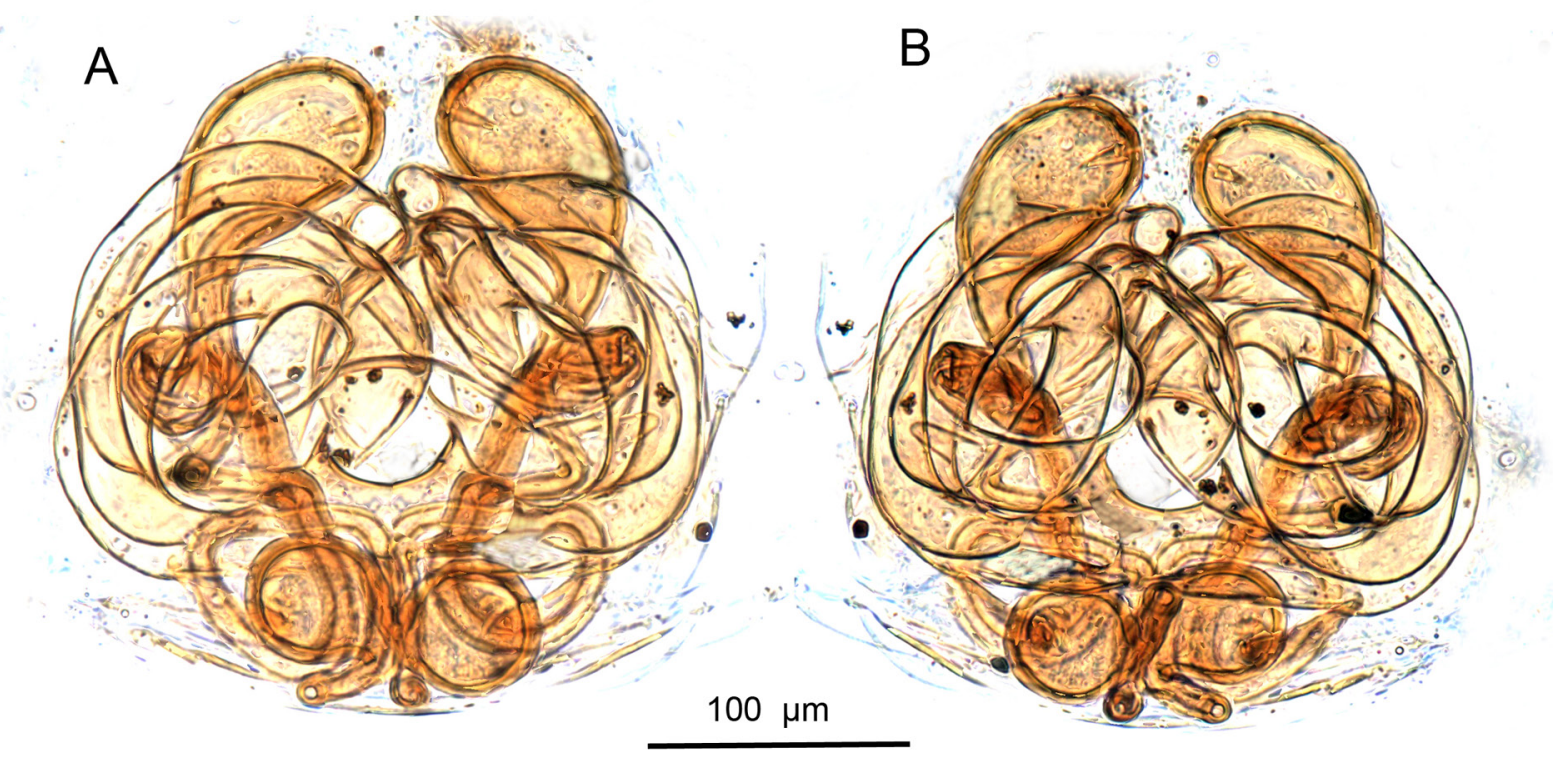

Fig. 3. Hortipes gigapophysalis sp. nov. A. Epigyne cleared in methyl salicylate, ventral view. B. idem, dorsal view. 


\section{Discussion}

The RTA is usually a solid, strongly sclerotized structure. Its main function was long thought to be internally stabilising the expanded male palp during copulation, which means that the RTA locks either specific sclerites of the bulbus or between the bulbus and cymbium in order to arrest further rotation or movement (Huber 1995a: 151; Sierwald \& Coddington 1988: 264). However, the RTA has been found to fulfill many different functions. Huber (1994) mentions four different functions for the RTA in one
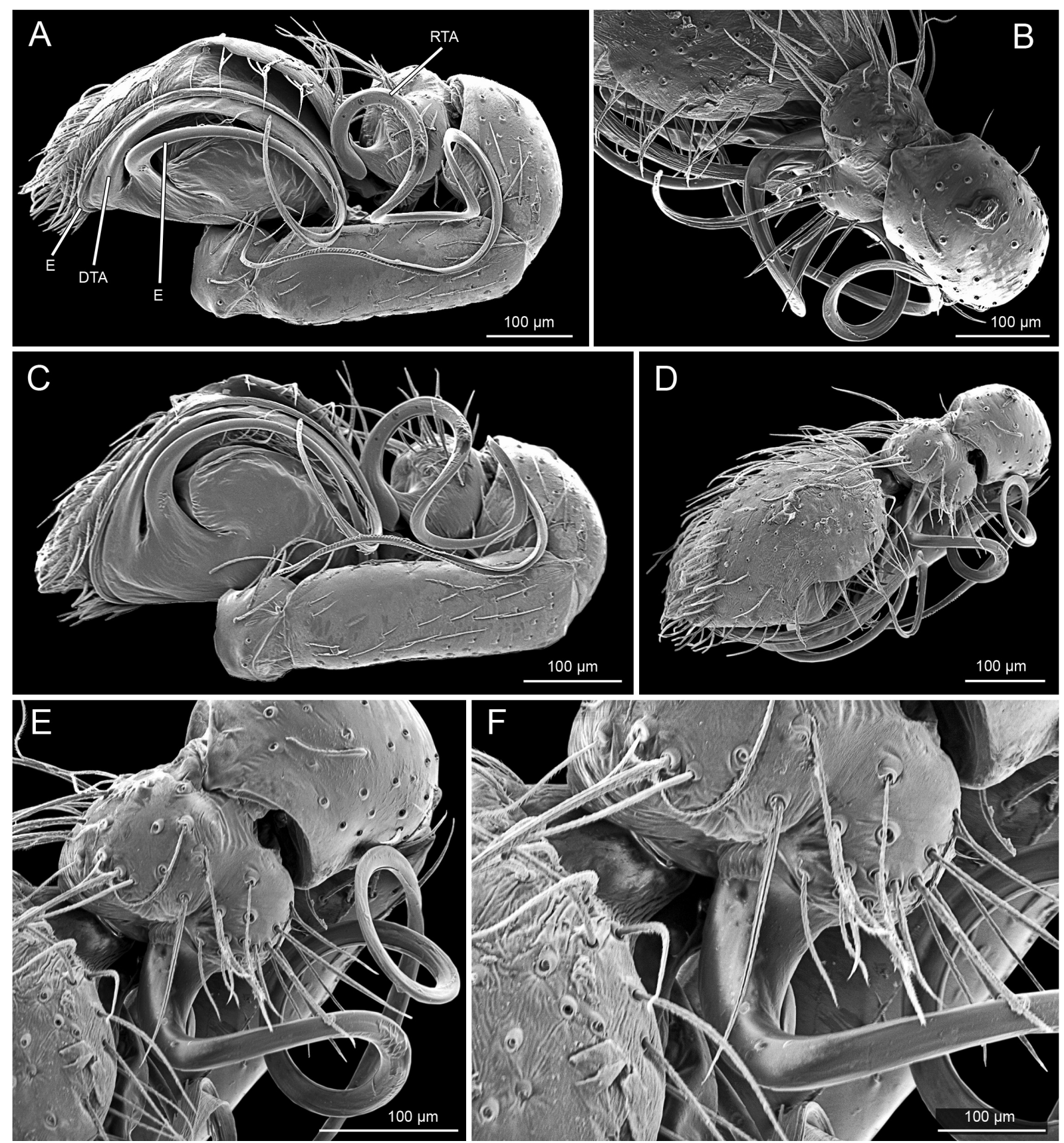

Fig. 4. Hortipes gigapophysalis sp. nov. A. Male palp, retrolateral view. B. Male palpal patella and tibia, dorsal view. C. Male palp, ventral view. D. idem, dorsal view. E. Male palpal tibia and patella, dorsolateral view. F. Detail of previous. E: embolus, DTA: distal tegular apophysis, RTA: retrolateral tibial apophysis. 
single spider family (Agelenidae). In Textrix denticulata (Olivier, 1768), the RTA fixes the male palp to the female epigyne; in Histopona torpida (C.L. Koch, 1834) the role of the RTA is unclear, since the patellar apophysis arrests the male bulbus internally; in Agelena gracilis and Agelenopsis spp. the RTA locks the male palp internally in two different ways, as described below (Gering 1953; Osterloh 1922). Jäger (2006: 58) confirms this diversity in function, showing that the RTA anchors in the epigastric furrow in Sparassidae but anchors in the epigyne in Gnaphosidae. Huber (1995a) points out that the function of the RTA is highly species specific and may be involved in mate choice by physical contact during copulation (1995a: 152), rather than internally stabilising the male palp. Huber (1995a, 1995b: 698, fig. 5) demonstrated that the RTA is used to fix the male pedipalp to the female epigyne for six species from six different families of the RTA-clade (Coddington \& Levi 1991). Huber (1995a: 159160) also states that most data inferring that the RTA arrests the male bulb internally during copulation are doubtful for methodological reasons. Either the authors used artificially expanded genital bulbs, or they studied genital bulbs fixed in copula, but sprung away from the epigyne. The vast majority of research using reliable methodology (observations of animals in copula, sections of animals fixed in copula) led to the conclusion that the RTA fixes the male pedipalp to the female externally. Such fixation to the female epigyne may be necessary because of the lack of innervation of the male bulbus (Eberhard \& Huber 1998).

Huber cites the studies of Osterloh (1922) and Gering (1953) as exceptions to this generalisation, and lists them in his table 1 as an RTA that arrests the genital bulb internally in Agelena gracilens C.L. Koch, 1841 and Agelenopsis spp. Giebel, 1869, respectively. More specifically, Osterloh (1922: 348) states that the RTA is inserted between the palpal bulbus ("Kapsel") and the palpal terminal sclerites ("Stema") in copula, and that only the terminal sclerites ("Alles, was zum Stema gehört") are introduced into the

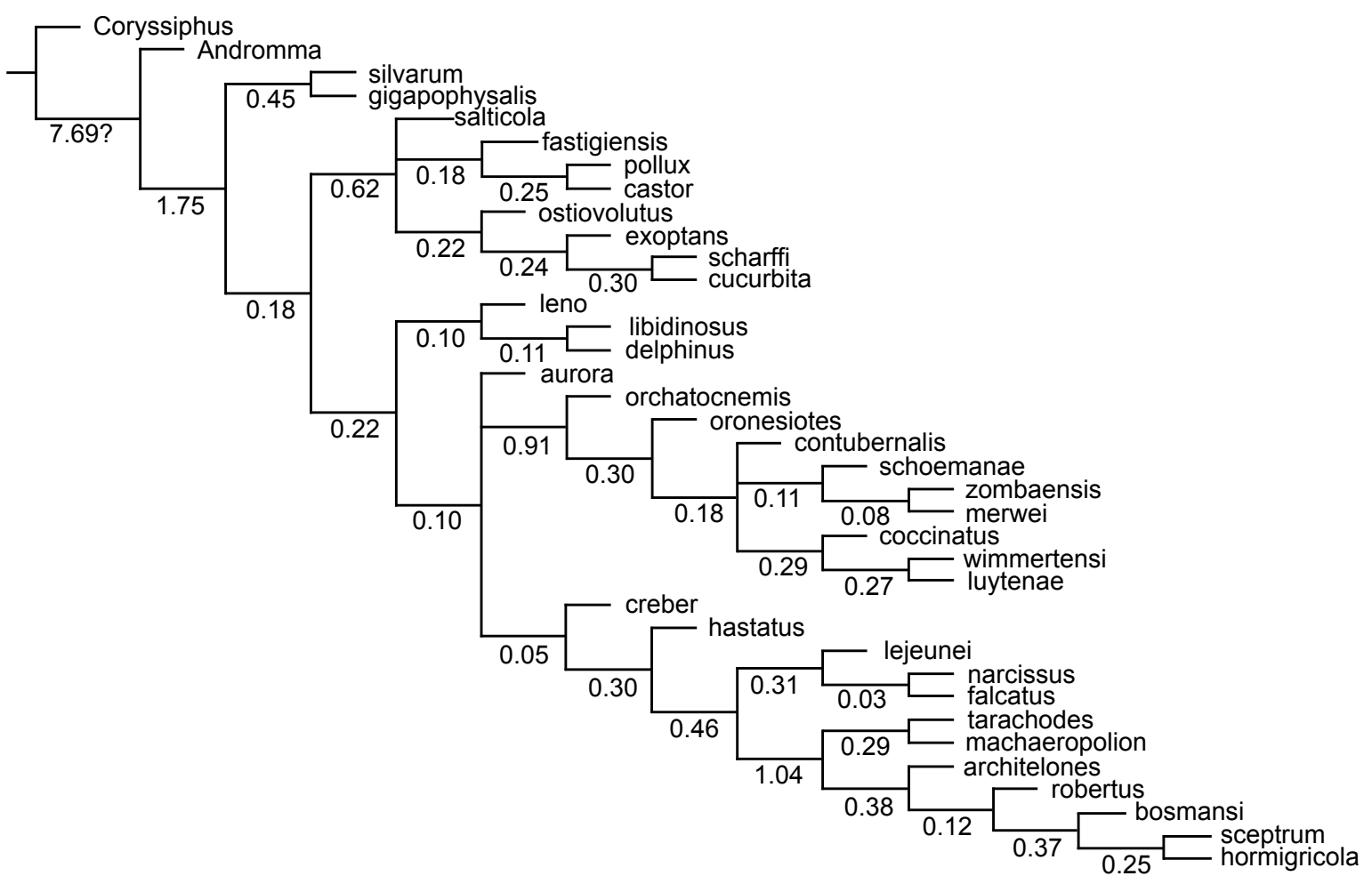

Fig. 5. Cladogram obtained from the character matrix in Bosselaers \& Jocqué (2000) with inclusion of H. gigapophysalis. Strict consensus of 18 trees of fit -53.061 (PAUP values), obtained under implied weighting. Bremer support values are shown under the branches. 
epigyne. Locking of the male palpus to the epigyne in these two species is performed by the patellar apophysis, not the RTA (1922: 390). Gering (1953: 13) states: "The ectoproximal margin of the cymbium has a weakly produced depression, which normally is somewhat more heavily pigmented and sclerotized than the surrounding area (figs 11-12, 39). The tibial process rests in this depression when the palpus is locked." We can conclude that neither author clearly advocates that the RTA is introduced into the internal female genital organs. In Gnaphosidae the RTA, a "primary anchoring device to the epigynal pocket" (Senglet 2004: 87) does not take part in intromission, which takes place after the palpus is fixed (Senglet 2004: 91).

However, in the present contribution, an RTA is described which has exactly this very unusual function: intromission into the female genital organs. To the best of our knowledge, such a use of the RTA has never been mentioned before. As the RTA of H. gigapophysalis sp. nov. is very long, thin and supple, it is very unlikely that it is used as a rigid locking device as described above. Its analogy with the embolus, a long whiplike, supple structure, made us suspect that it might be an insertable sclerite. Detailed study of the epigyne indeed reveals the presence of two independent tubular systems. The first is the usual insemination duct starting at a lateral slit-like entrance and leading to two sets of spermathecae (Fig. 2C, D). The second is composed of wide, very simple, thin-walled tubes starting from funnelshaped entrances in a central concavity, ending blind at the end of several bends without connection with the first system (Fig. 2E, F). It is assumed that the second system is meant to receive the RTA.

Hortipes is a genus with an amazing genitalic variability. Nevertheless, not a single species with an RTA that is clearly insertable in the female genitalia has been described to date. Among the known species (Bosselaers \& Jocqué 2000a; Ledoux \& Emerit 1998), only a few species of the orchatocnemis clade (node 12 in Bosselaers \& Jocqué 2000a, fig. 4) have vulvae that, in view of their weakly sclerotised entrance chamber (Bosselaers \& Jocqué 2000a: 14, character 65) show possible evidence of additional sclerites being inserted during copulation. H. merwei Bosselaers \& Jocqué, 2000, for example, has an elaborate lobed entrance chamber (Bosselaers \& Jocqué 2000a: fig. 20e) that seems especially suited for insertion of the exceptionally large, flexible and coiled MA of the male palp (Bosselaers \& Jocqué 2000a: fig. 19a, b). Jäger (2012: figs 19, 23) describes Sinopoda vulvae with similar thin-walled sacs. In this genus, these sacs proved to be expandable, but Jäger does not mention any role for them. The entrance chamber of $H$. aelurisiepae Bosselaers \& Jocqué, 2000, also has peculiar thin-walled lobes, lateral in this case, that might receive an additional palpal sclerite from the unknown male. However, none of the Hortipes species described to date have an RTA of considerable length that matches a vulvar structure in which it could be inserted. Moreover, as a result of the fact that the Hortipes species of western Africa are very poorly sampled (Bosselaers \& Jocqué 2000a: map 1), no intermediate stages are known between the genitalia of the species already described and the insertable RTA of $H$. gigapophysalis sp. nov. Based on leg spination and genitalic structure, $H$. gigapophysalis sp. nov. seems closest to H. hesperoecius Bosselaers \& Jocqué, 2000 and H. silvarum. Repeating the cladistic analysis of Hortipes species known from both sexes (Bosselaers \& Jocqué 2000a), including H. gigapophysalis sp. nov., confirms this (Fig. 5): H. gigapophysalis sp. nov. turns out to be the sister species of H. silvarum and is situated at the base of the Hortipes clade in the strict consensus of 18 trees of fit -53.061 (PAUP values), obtained under implied weighting (Fig. 5). In the strict consensus of 1656 shortest trees of length 265 obtained under equal weighting, the salticola clade (node 3 in Bosselaers \& Jocqué 2000a, fig. 4) holds a still more basal position within Hortipes, but the sister species relationship between $H$. silvarum and $H$. gigapophysalis is confirmed. However, although $H$. silvarum has a relatively slender and apically coiled RTA (Bosselaers \& Jocqué 2000a: fig. 12e, f), it has no vulvar tubes in which the RTA could be inserted (Bosselaers \& Jocqué 2000a: fig. 13d). Only more extensive sampling of the forest litter layer of tropical western Africa may produce the as yet unknown Hortipes species allowing to reconstruct the phylogeny of this most unusual genitalic development. 


\section{Acknowledgements}

We are indebted to Alain Reygel for the drawings of the genitalia. We thank P. Jäger and an anonymous referee for useful comments on a previous version. This research was supported by Golder Associates and sub-consultants as a component of the Nimba Project ESIA for Société des Mines de Fer de Guinée. This paper is publication BRC 277 of the Biodiversity Research Center (Université catholique de Louvain).

\section{References}

Bonaldo A.B. 1997. On the neotropical genus Ianduba (Araneae, Corinnidae). Iheringia, Serie Zoologia 83: $165-180$.

Bosselaers J. \& Jocqué R. 2000a. Hortipes, a huge genus of tiny African spiders (Araneae, Liocranidae). Bulletin of the American Museum of Natural History 256: 1-108. http://dx.doi.org/10.1206/00030090(2000)256\%3C0004:HAHGOT\%3E2.0.CO;2

Bosselaers J. \& Jocqué R. 2000b. Studies in Corinnidae: transfer of four genera and description of the female of Lessertina mutica Lawrence 1942. Tropical Zoology 13: 305-325.

Bosselaers J. \& Ledoux J.-C. 1998. Description of a new African genus, Hortipes (Araneae, Liocranidae). Revue d'Arachnologie 12 (14): 147-152.

Bremer K. 1988. The limits of amino acid sequence data in angiosperm phylogenetic reconstruction. Evolution 42: 795-803.

Bremer K. 1994. Branch support and tree stability. Cladistics 10: 295-304.

Bugnion E., Devine S. \& Rosenblum M. 2000. Virtual machine monitors for scalable multiprocessors. US patent $6,075,938,15 \mathrm{pp}$.

Coddington J.A. \& Levi H.W. 1991. Systematics and Evolution of Spiders (Araneae). Annual Review of Ecology and Systematics 22: 565-592. http://dx.doi.org/10.1146/annurev.es.22.110191.003025

Eberhard W.G. \& Huber B.A. 1998. Possible links between embryology, lack of innervation, and the evolution of male genitalia in spiders. Bulletin of the British arachnological Society 11 (2): 73-80.

Gering R. L. 1953. Sructure and function of the genitalia in some American agelenid spiders. Smithsonian miscellaneous Collections 121 (4): 1-84.

Goloboff P.A. 1993. Estimating character weights during tree search. Cladistics 9: 83-91.

Goloboff P.A., Farris J.S. and Nixon K.C. 2003. TNT, Tree Analysis using New Technology. Version 1.1, sponsored by the Willy Hennig Society. Available from: http://www.cladistics.com (2008-12-30).

Goloboff P.A., Farris J.S. \& Nixon K.C. 2008. TNT, a free program for phylogenetic analysis. Cladistics 24: 774-786.

Huber B.A. 1994. Copulatory mechanics in the funnel-web spiders Histopona torpida and Textrix denticulata (Agelenidae, Araneae). Acta Zoologica 75 (4): 379-384.

Huber B.A. 1995a. The retrolateral tibial apophysis in spiders - shaped by sexual selection? Zoological Journal of the Linnean society 113: 151-163.

Huber B.A. 1995b. Genital morphology and copulatory mechanics in Anyphaena accentuata (Anyphaenidae) and Clubiona pallidula (Clubionidae: Araneae). Journal of Zoology, London 235: 689702.

Jäger P. 2006. Lengthening of embolus and copulatory duct: a review of an evolutionary trend in the spider family Sparassidae (Arachnida: Araneae). In: Deltshev C. \& Stoev P. (eds) European Arachnology 2005. Acta Zoologica Bulgarica Suppl. No 1: 49-62. 
Jäger P. 2012. Revision of the genus Sinopoda Jäger, 1999 in Laos with discovery of the first eyeless huntsman spider species (Sparassidae: Heteropodinae). Zootaxa 3415: 37-57.

Jocqué R. 2002. Genitalic polymorphism - a challenge for taxonomy. Journal of Arachnology 30: 298306. http://dx.doi.org/10.1636/0161-8202(2002)030[0298:GPACFT]2.0.CO;2

Jocqué R. \& Bosselaers J. 2011. Revision of Pseudocorinna Simon and a new related genus (Araneae: Corinnidae): two more examples of spider templates with a large range of complexity in the genitalia. Zoological Journal of the Linnean Society 162: 271-350. http://dx.doi.org/10.1111/j.1096$\underline{3642.2010 .00679 . x}$

Ledoux J.-C. \& Emerit M. 1998. Quelques espèces du genre africain Hortipes Bosselaers \& Ledoux et leur coupelle métatarsale (Araneae, Liocranidae?). Revue arachnologique 12: 153-168.

Osterloh A. 1922. Beiträge zur Kenntnis des Kopulationsapparates einiger Spinnen. Zeitschrift für wissenschaftliche Zoologie 119: 326-421.

Platnick N.I. \& Shadab M.U. 1975. A revision of the spider genus Gnaphosa (Araneae, Gnaphosidae) in America. Bulletin of the American Museum of Natural History 155: 1-66.

Senglet A. 2004. Copulatory mechanisms in Zelotes, Drassyllus and Trachyzelotes (Araneae, Gnaphosidae), with additional faunistic and taxonomic data on species from southwest Europe. Mitteilungen der Schweizerischen Entomologischen Gesellschaft 77: 87-119.

Sierwald P. \& Coddington J.A. 1988. Functional aspects of the male palpal organ in Dolomedes tenebrosus, with notes on the mating behavior (Araneae, Pisauridae). Journal of Arachnology 16: 262265.

Manuscript received: 8 September 2012

Manuscript accepted: 20 October 2012

Published on: 31 October 2012

Topic editor: Koen Martens

In compliance with the $I C Z N$, printed versions of all papers are deposited in the libraries of the institutes that are members of the EJT consortium: Muséum National d'Histoire Naturelle, Paris, France; National Botanic Garden of Belgium, Meise, Belgium; Royal Museum for Central Africa, Tervuren, Belgium; Natural History Museum, London, United Kingdom; Royal Belgian Institute of Natural Sciences, Brussels, Belgium; Natural History Museum of Denmark, Copenhagen, Denmark. 